CHAPTER 4:

\title{
The Influence of Students" Personal and Home Background on Computer and Information Literacy
}

Many studies (among them those by Bradley \& Corwyn, 2002; Saha, 1997) show that students' personal and home background influences their acquisition of knowledge as well as other learning outcomes. Among the student background factors found to be statistically significantly associated with educational achievement are gender, parental socioeconomic status, language used at home, ethnicity, and whether or not the student and/or his or her parents have an immigrant background. Research also provides evidence of the particular impact that students' respective socioeconomic backgrounds have on their achievement. This association has been observed across many learning areas (see, for example, Saha, 1997; Sirin, 2005; Woessmann, 2004).

According to more recent research studies, home background factors also influence the learning of information and communication technology (ICT) skills (Ministerial Council for Education, Early Childhood Development and Youth Affairs [MCEECDYA], 2010; Nasah, DaCosta, Kinsell, \& Seok, 2010). Evidence from many countries highlights considerable disparities in students' access to digital resources at home. Both researchers and commentators claim that these disparities affect the opportunities students have to develop the capabilities required for living in modern societies (Warschauer \& Matuchniak, 2010).

Given this body of research, the ICILS research team deemed inclusion of an additional home factor of particular importance when reviewing the association between home background and communication and information literacy (CIL). That factor was the extent to which students have access to ICT resources in their respective homes.

In this chapter, we investigate ICILS survey data with regard to Research Question 4: What aspects of students' personal and social background (such as gender, socioeconomic background, and language background) are related to computer and information literacy? In order to help answer this question, we reviewed potential associations between CIL achievement and gender as well as between CIL and four types of indicators of students' home background.

1. Educational aspirations (expected highest educational attainment);

2. Socioeconomic background (parental occupation, parental education, and number of books at home);

3. Immigrant status and language use; and

4. Home-based IT resources (number of computers or laptops and internet access at home).

After reviewing the bivariate relationships between each of the indicators and the CIL test scores, we report the results of a multivariate regression analysis that we conducted in order to (1) explore the influence of different indicators on CIL after we had controlled for all other indicators, and (2) how much three different types of factor (students' personal background, socioeconomic background, and home ICT resources) 
contributed to the explanation of variation in CIL. We chose not to include immigrant status and language in the multivariate analysis because many of the ICILS countries had only very small numbers of immigrants or students who spoke languages other than the language of the ICILS assessment at home.

\section{Gender and CIL}

Many studies on educational achievement across a broad range of learning areas show differences in achievement between females and males. While crossnational research on reading literacy at most school levels shows larger gender differences in favor of females, males tend to be somewhat more proficient in learning areas such as mathematics and science (Mullis, Martin, Kennedy, \& Foy, 2007; OECD, 2010). Results from Australian assessments of ICT literacy in 2008 and 2011 showed significantly higher levels of achievement for females when compared to male students in both Grade 6 and Grade 10 (Australian Curriculum, Assessment and Reporting Authority, 2012; MCEECDYA, 2010).

Table 4.1 shows the average scores of female and male students in each country. The average CIL scale scores of female students were statistically significantly higher than those of male students in all countries except Turkey and Thailand. In these two countries, there was no statistically significant difference between the average scores of female students and male students. The international average score for female students was 509 scale points, and for male students it was 491 scale points-a difference of 18 scale points, equivalent to about one fifth of the ICILS standard deviation.

The magnitude of the statistically significant differences in achievement between female and male students within countries ranged from 12 scale points in the Czech Republic to 38 scale points in Korea. ${ }^{1}$ We observed no evidence across most countries of systematic relationships between the magnitude of differences in achievement by geographical location or average scale score.

\section{Home background indicators and CIL}

\section{Educational aspirations}

Students' aspirations with regard to their education was another variable that ICILS viewed as important when analyzing variation in student CIL. We can reasonably assume that students' home environment, interests, previous study results at school, and sense of their own success at school influence their expectations of undertaking further studies. Various research studies show associations between expectations and achievement in several learning areas (Valentine, DuBois, \& Cooper, 2004).

One of the questions in the ICILS student questionnaire asked students to state the level of educational qualification they expected to attain. In order to aid our analysis of students' reponses to this question, we used the International Standard Classification of Education (ISCED: UNESCO, 2006) to define categories for the levels of educational attainment but first asked the study's national research centers to adapt these to local contexts. 


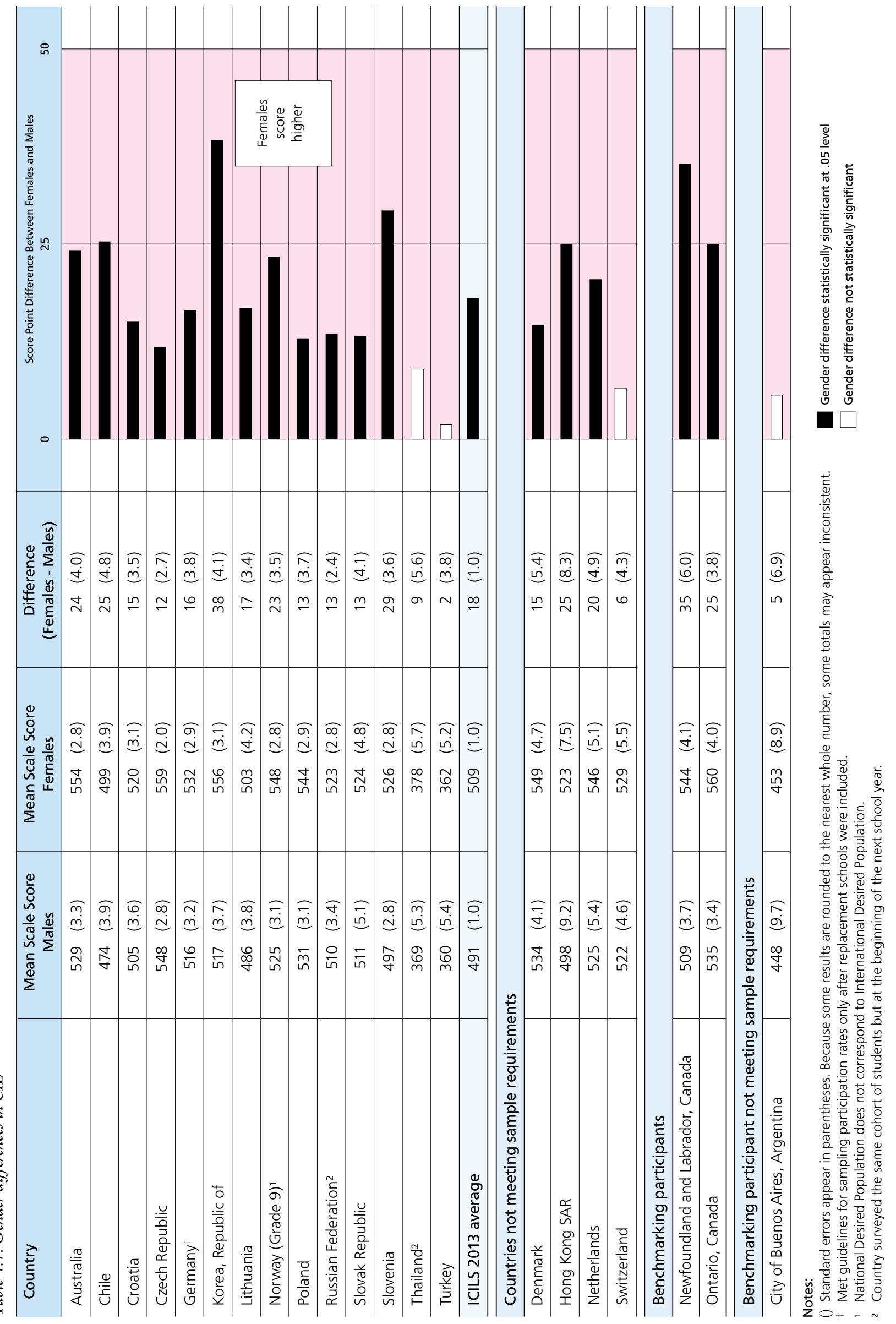


Students were asked whether they expected to complete a tertiary university degree (ISCED Level 5A or 6), a post-secondary nonuniversity degree (ISCED Level 4 or 5B: for example, at a technical college), an upper-secondary degree (ISCED Level 3: general, prevocational, or vocational), a lower-secondary degree (ISCED Level 2), or whether they did not expect to finish lower-secondary schooling. Given the low numbers of students who did not expect to complete lower-secondary education, we combined the last two categories into one (students who did not expect to complete any education beyond lower-secondary).

Table 4.2 shows the percentages in each reporting category, the average CIL score for students in each category, and the overall differences between the highest (university degree) and lowest categories (lower-secondary education or below). On average across the participating countries, about half of the students expected to complete university education, 17 percent expected to attain a post-secondary nonuniversity degree, and 24 percent to obtain an upper-secondary qualification. Eight percent expected to go no further than lower-secondary education. However, large expectation differences were evident across the ICILS education systems (see Table 4.2). For example, while three quarters of Korean students expected to obtain a university degree, only one in five German students expected to do so.

Generally, CIL average scores increased with levels of expected educational attainment. Across participating countries, the difference in CIL scores between students not expecting to have a qualification beyond lower-secondary education and those expecting to complete university was, on average, 89 score points. The range in score points extended from 54 in the benchmarking participant Newfoundland and Labrador (Canada) and 65 in the Czech Republic to 112 in Croatia and 113 in the Slovak Republic. In a few countries, there was no increase in CIL scores from the "expect to complete upper-secondary" category to the "expect to complete post-secondary nonuniversity" category.

\section{Socioeconomic background}

Socioeconomic background is a construct regarded as manifest in occupation, education, and wealth (Hauser, 1994). While it is widely regarded internationally as an important correlate of a range of learning outcomes (Sirin, 2005; Woessmann, 2004), there is no scholarly consensus on which measures should be used for capturing family background (Entwistle \& Astone, 1994; Hauser, 1994) and no agreed standards for creating composite measures of socioeconomic status (Gottfried, 1985; Mueller \& Parcel, 1981). Furthermore, in the context of international studies, there are caveats relating to the validity and crossnational comparability of socioeconomic background measures (Buchmann, 2002). In this chapter, our consideration of the influence of socioeconomic background on CIL focuses on within-country associations between indicators of socioeconomic status and test performance.

In order to gather information on the educational attainment of students' parents, the ICILS student questionnaire asked students to identify their parents' level of attainment on a list of predefined categories. These categories drew on the ISCED definitions and included tertiary university degree (ISCED $5 \mathrm{~A}$ or 6 ), post-secondary nonuniversity degree (ISCED 4 or 5B), upper-secondary completion (ISCED 3), lower-secondary completion (ISCED 2), and incomplete lower-secondary education (OECD, 1999; UNESCO, 2006). 


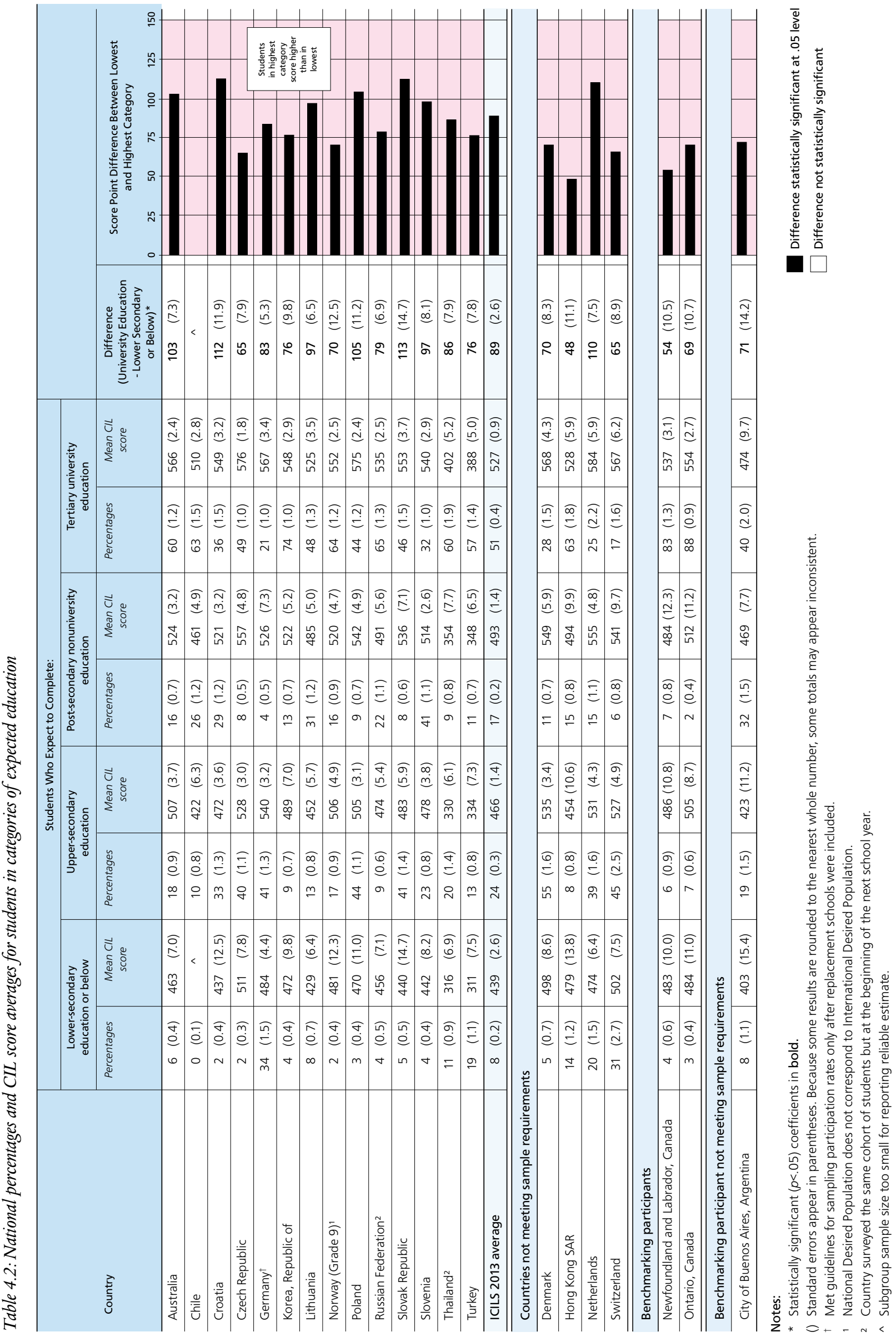


Where students provided data for both their parents, we used the highest ISCED level as the indicator of parental educational attainment. Given the very low percentages of students with parents who had not attained lower-secondary education, we combined the two last categories and referred to the new one as lower-secondary education or below. On average across the ICILS countries, 99 percent of students provided valid parental education data, reflecting the fact that computer-administered questionnaires generally facilitate high response rates.

Table 4.3 records the percentages of students in the categories denoting parental highest educational level, as well as the average CIL scores within each category. It also shows the results from a bivariate regression of CIL on highest parental education (in approximate years of schooling).

Across participating countries, 15 percent of students, on average, had parents who had not completed an educational level higher than lower secondary, 33 percent had at least one parent with an upper-secondary qualification, 17 percent had at least one parent with a post-secondary nonuniversity degree, and 35 percent had at least one parent with a university degree. There was considerable variation across the participating countries. In most countries, the percentages of students with parents whose educational attainment reached no higher than the lower-secondary level were below 10 percent. In Thailand and Turkey, however, the corresponding percentages were 50 percent and 59 percent respectively. In Korea, Norway, Ontario (Canada), and the Russian Federation, more than half of the students reported having at least one parent with a university degree, whereas only a fifth of the students or fewer reported this in Thailand and Turkey. The percentages for parental education in Germany suggest that the ISCED categories may not have adequately captured this country's dual system of vocational and academic qualifications.

In all countries, we observed a pattern wherein CIL scores increased in correspondence with increased parental educational attainment. On average across ICILS countries, we found a difference of 72 CIL score points between students with at least one parent who had a university education and those whose parents had not attained a qualification beyond lower secondary. These score differences ranged from 39 score points in Korea to 132 score points in the Slovak Republic.

The ICILS student questionnaire collected data on parental occupational status through questions that allowed students to give open-ended responses. The students' responses were classified during the analysis process according to the International Standard Classification of Occupations (ISCO-08) framework (International Labour Organization, 2007). Research indicates relatively high consistencies between data on parental occupation collected from students and from parents (Schulz, 2006; Vereecken \& Vandegehuchte, 2003).

To generate a continuous measure of occupational status, Ganzeboom, de Graaf, and Treiman (1992) coded the ISCO codes in order to derive their International Socioeconomic Index (SEI). The SEI provides a crossnationally comparable framework for organizing occupations in a hierarchical order according to their occupational status. We assigned SEI scores to each parent's occupation and then, for each student with two parents, took the higher of the two SEI scores as the indicator score. For students from single-parent families, the one score served as the indicator. 


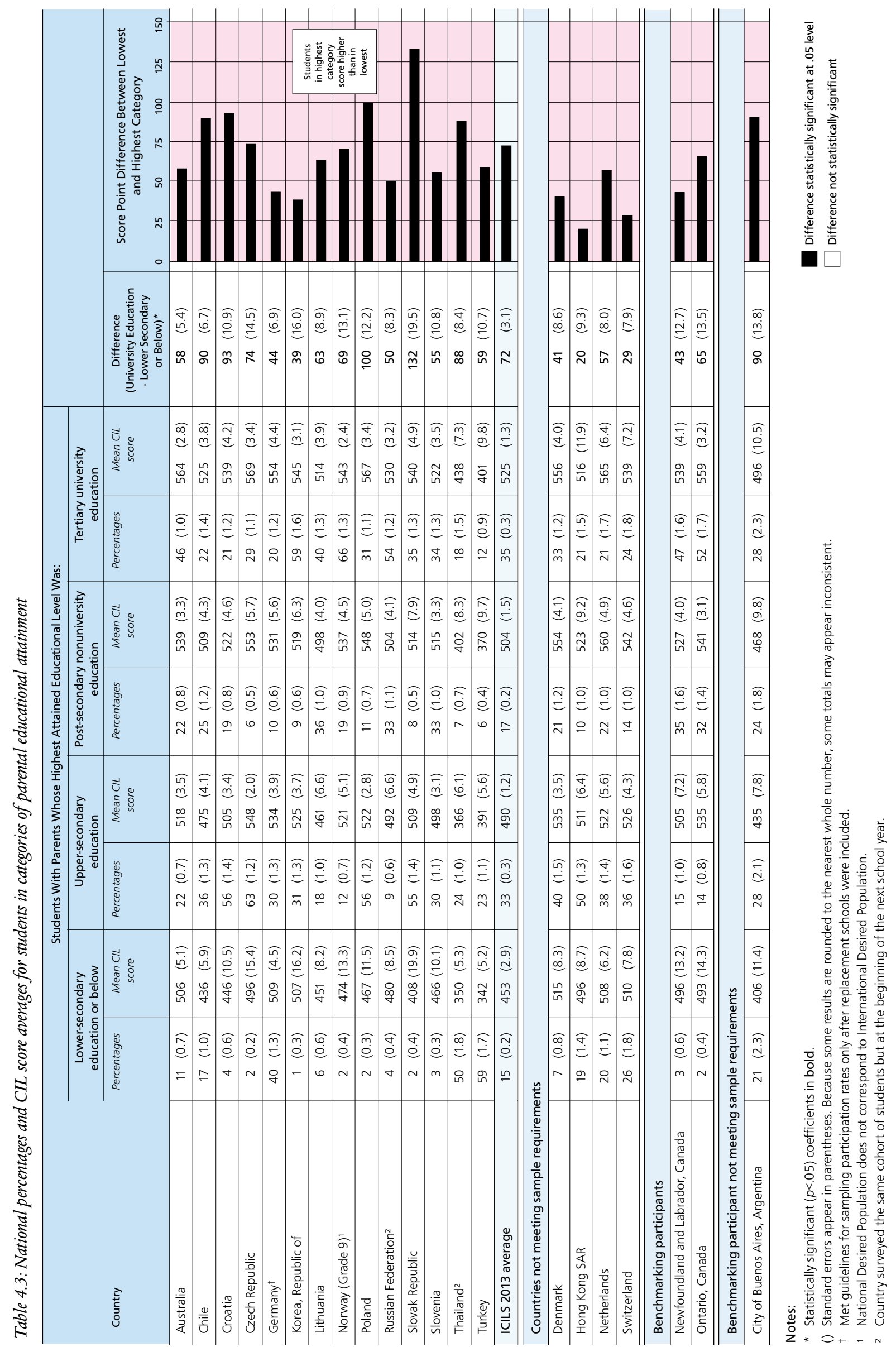


The SEI scale is continuous and ranges from 16 to 90 score points. To describe the parental occupation results in terms of broader categories, we divided the SEI scale into three groups based on international cut-off points. These were "low occupational status" (below 40 score points), "medium occupational status" (40 to 59 score points), and "high occupational status" (60 score points or more). On average across the ICILS countries, valid SEI scores were available for 95 percent of the participating students. The Netherlands did not provide data on parental occupation and so were excluded from this analysis.

To assess the influence of parental occupational status on CIL, we estimated bivariate regression models with highest parental occupation as a predictor. We derived the predictor variable by transforming the original SEI scores to a metric in which a value of zero corresponded to the mean and a value of one to the standard deviation for the combined ICILS database of equally weighted national samples meeting sampling requirements.

Table 4.4 shows the percentage of students with parents in each occupational status category as well as the average CIL scores for the students in each of these groups. Across participating ICILS countries, 39 percent (on average) of students reported that their parents were in the lowest occupational status category (SEI below 40), 37 percent identified their parents as being in the middle category (40 to 59), and 24 percent placed their parents in the highest category (SEI 60 and above). However, there were substantial differences in the distribution across countries. In Thailand and Turkey, over 60 percent of the students had parents in the lowest occupational status group; in Korea, Norway, and Ontario (Canada), only about one fifth of the students had parents in this category.

In all participating countries, the average CIL scores were lowest in the occupational status group with SEI scores below 40 and, with the exception of Hong Kong SAR, highest in the group with SEI scores of 60 and above. On average across participating countries, the difference between students in the highest and lowest parental occupation categories was 54 CIL score points, with differences ranging from 26 score points in Korea to 96 score points in Thailand.

To measure home literacy resources as an additional indicator of students' socioeconomic (and cultural) background, the ICILS student questionnaire asked students to report the number of books (broken down into five categories) in their respective homes. Response categories were " 0 to 10 books," " 11 to 25 books," " 26 to 100 books," "101 to 200 books," and "more than 200 books." Given that our exploratory analyses showed only minor CIL score differences between the highest two categories, we combined these into one reporting category labeled "more than 100 books." On average across countries, 99 percent of the ICILS students had valid data for this indicator. Even with the advent of electronic books, and although the average number of printed books in homes appears to have decreased over time, we consider that number of books at home is a valid indicator of home literacy resources because it continues to be consistently correlated with educational achievement.

Table 4.5 shows the percentage of students in each category together with the average CIL score by category. The table also presents the results from our bivariate regression model, developed in order to determine the effect of home literacy resources on CIL. 


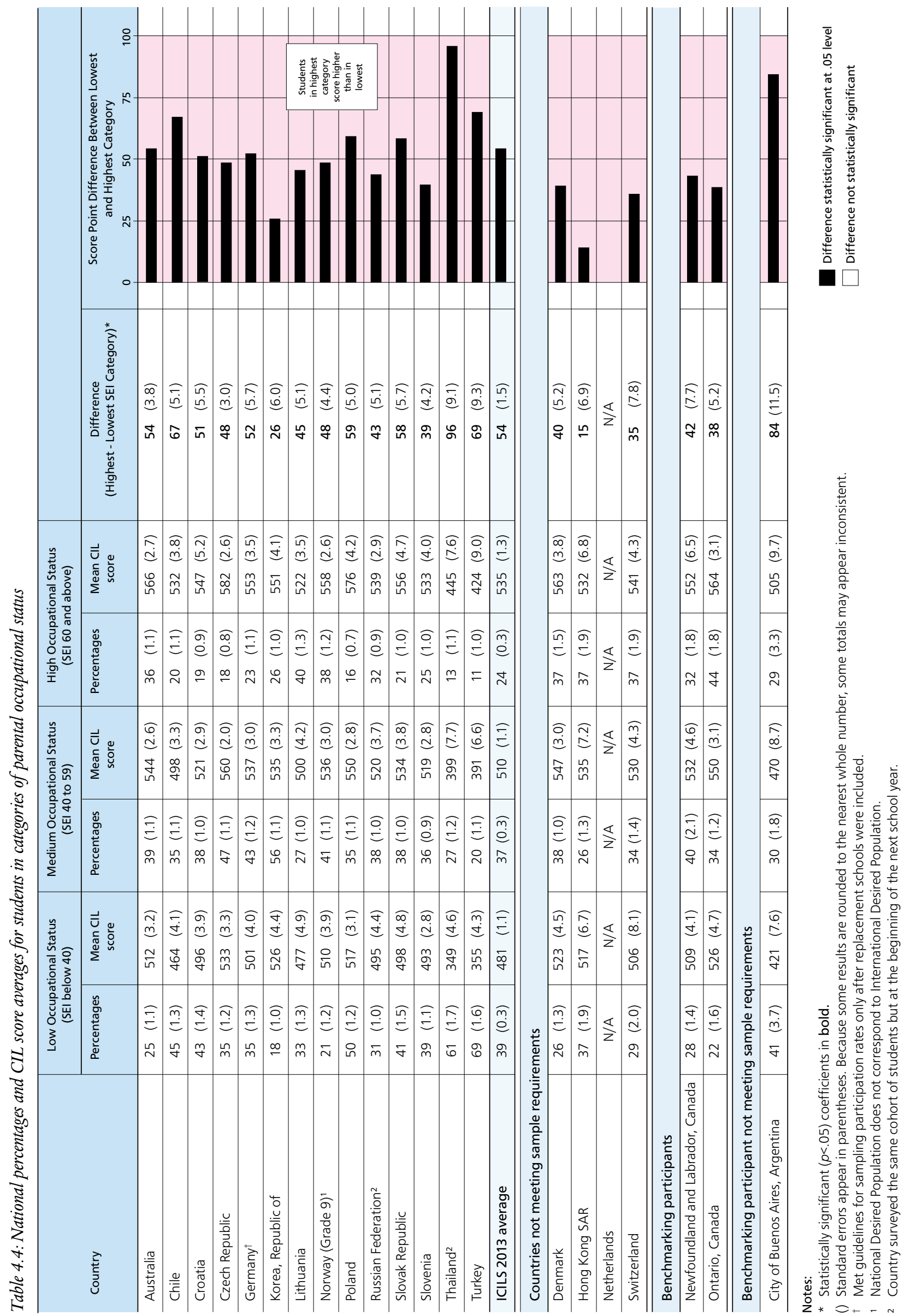




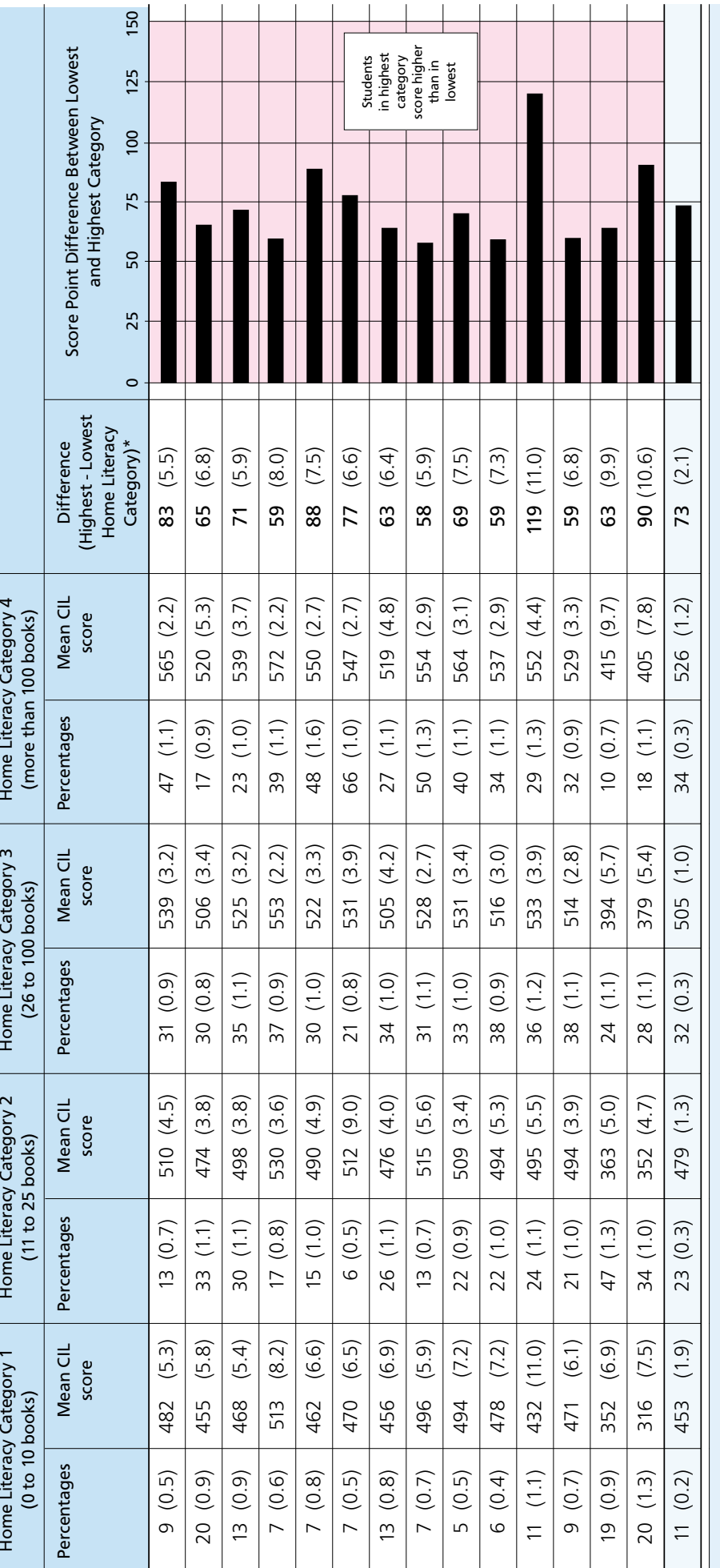
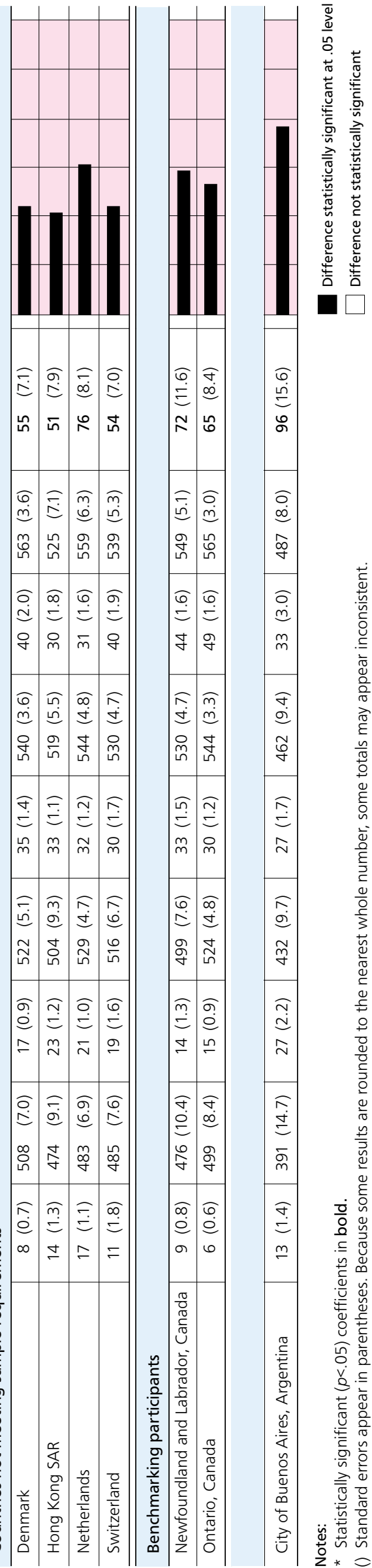
Across countries, the average percentages for books in the home were 11 percent for 10 or fewer books, 23 percent for between 11 and 25 books, and 32 percent for between 26 and 100 books. An average of 34 percent of students reported more than 100 books at home. There was again a high level of variation across countries. In Chile, Thailand, and Turkey, about every fifth student had fewer than 10 books in his or her home. Less than 20 percent of the students in these countries were living in homes with more than 100 books. In contrast, in Australia, Germany, Norway, Korea, and Ontario (Canada), almost half or more of the ICILS students reported having 100 or more books in their homes.

Students from homes with the higher numbers of books tended to have higher CIL scores. Across the ICILS countries, the difference between students reporting more than 100 books at home and those reporting 10 or fewer was, on average, 73 CIL score points. The differences ranged from 58 score points in Norway and 59 in the Czech Republic, the Russian Federation, and Slovenia to 119 in the Slovak Republic.

\section{IImmigrant status and language use}

Many studies provide evidence of the influence of students' cultural and language background on their educational performance (see, for example, Elley, 1992; Kao, 2004; Kao \& Thompson, 2003; Stanat \& Christensen, 2006; Mullis et al., 2007). Students from immigrant families, especially those families recently arrived in a country, often lack proficiency in the language of instruction and may be unfamiliar with the norms of the dominant culture. Ethnic minorities also tend to have a lower socioeconomic status, which in turn is often negatively associated with learning and engagement. A number of studies indicate that when socioeconomic background is controlled for, immigrant status and language provide unique predictors of students' literacy achievement (Lehmann, 1996).

As a means of measuring these aspects of student background, the ICILS student questionnaire asked students about their own and their parents' countries of birth. The questionnaire also asked students to specify which language was spoken most frequently at home.

We created an index of students' immigrant status based on the information students provided about their country of birth and their parents' respective country of birth. We then recoded these data into categories that specified whether students had a solely immigrant background (both of the parents in two-parent households or the one parent in single-parent households born in another country) ${ }^{2}$ or without a solely immigrant background (at least one parent born in the country of the test). ${ }^{3}$ Nearly all students across nearly all participating countries provided valid responses to these questions.

Table 4.6 shows the percentages of students in the two immigrant background categories as well as the average CIL score in each category. The table also records the differences in average CIL scores between the two categories of students. Note that within each country, average CIL scores (and subsequently score point differences) are not reported for categories that have 30 students or less.

Variations across countries were large. While, in the majority of countries, more than 90 percent of the students did not have an immigrant background, in Australia,

2 This category is referred to as with an immigrant background.

3 This category is referred to as without an immigrant background. 


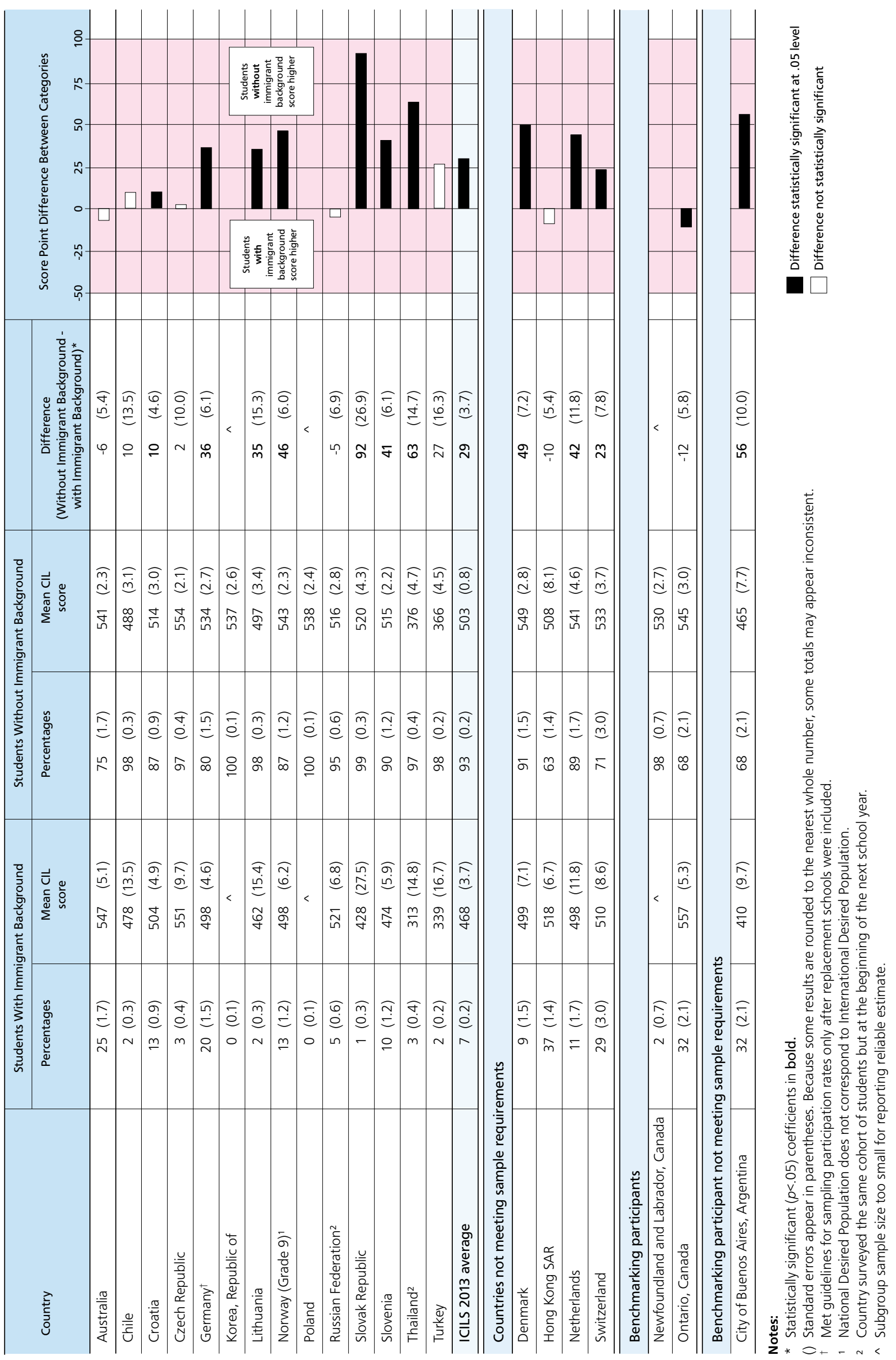


Croatia, Germany, Hong Kong SAR, the Netherlands, Norway, Ontario (Canada), and Switzerland, the proportions of students with an immigrant background were 10 percent or more.

In the countries other than those with very small numbers of students with immigrant backgrounds (Korea, Poland, and Newfoundland and Labrador), students without immigrant backgrounds tended to have higher CIL average scores than those with an immigrant background. On average across the participating countries, the difference between students with immigrant backgrounds and those without was 29 CIL score points, with the differences ranging from 10 score points in Croatia to 92 in the Slovak Republic. We found statistically significant effects in only seven of the 14 participating countries that met sampling requirements.

To investigate the influence of language use at home on CIL, we distinguished between students who reported using the test language at home and those who said they spoke a different language at home. Across countries, 99 percent of the students provided valid responses to this question. Table 4.7 shows the percentages and the average CIL scores for each category as well as the results of our bivariate regression of test scores on the language indicator variable.

In most participating countries, majorities of students indicated speaking the test language at home. In Australia, Germany, Lithuania, Norway, Hong Kong SAR, Switzerland, and Ontario (Canada), one tenth or more of the students reported speaking a language other than the test language at home. Across countries, CIL scores tended to be higher among students speaking the test language at home; the average difference was 31 score points. For eight of the 14 participating countries meeting sampling requirements, we recorded statistically significant differences between students speaking the test language and those speaking other languages at home. The statistically significant positive differences ranged from 25 score points in Croatia to 73 in the Slovak Republic.

\section{Home ICT resources}

To review the influence of IT resources at home on CIL, we chose two indicators. One was the number of computers at home; the other was the type of internet access available to students and their families.

Students were asked to report separately the number of desktop computers and the number of portable computers (notebooks, netbooks, and tablets) at home. We divided the sum of the two variables into the following categories: "no computers," "one computer," "two computers," and "three or more computers." On average across participating countries, 99 percent of the students provided data on the numbers of computers at home.

Table 4.8 shows the percentage in each reporting category along with the respective CIL score average and the results from an analysis that involved regressing the CIL scores on the indicator variable reflecting number of computers. Across countries, the average percentage of students who said there was no computer at home was only six percent. However, on average across countries, 48 percent of students had three or more computers at home, 24 percent had two computers at home, and 21 percent had one computer. 


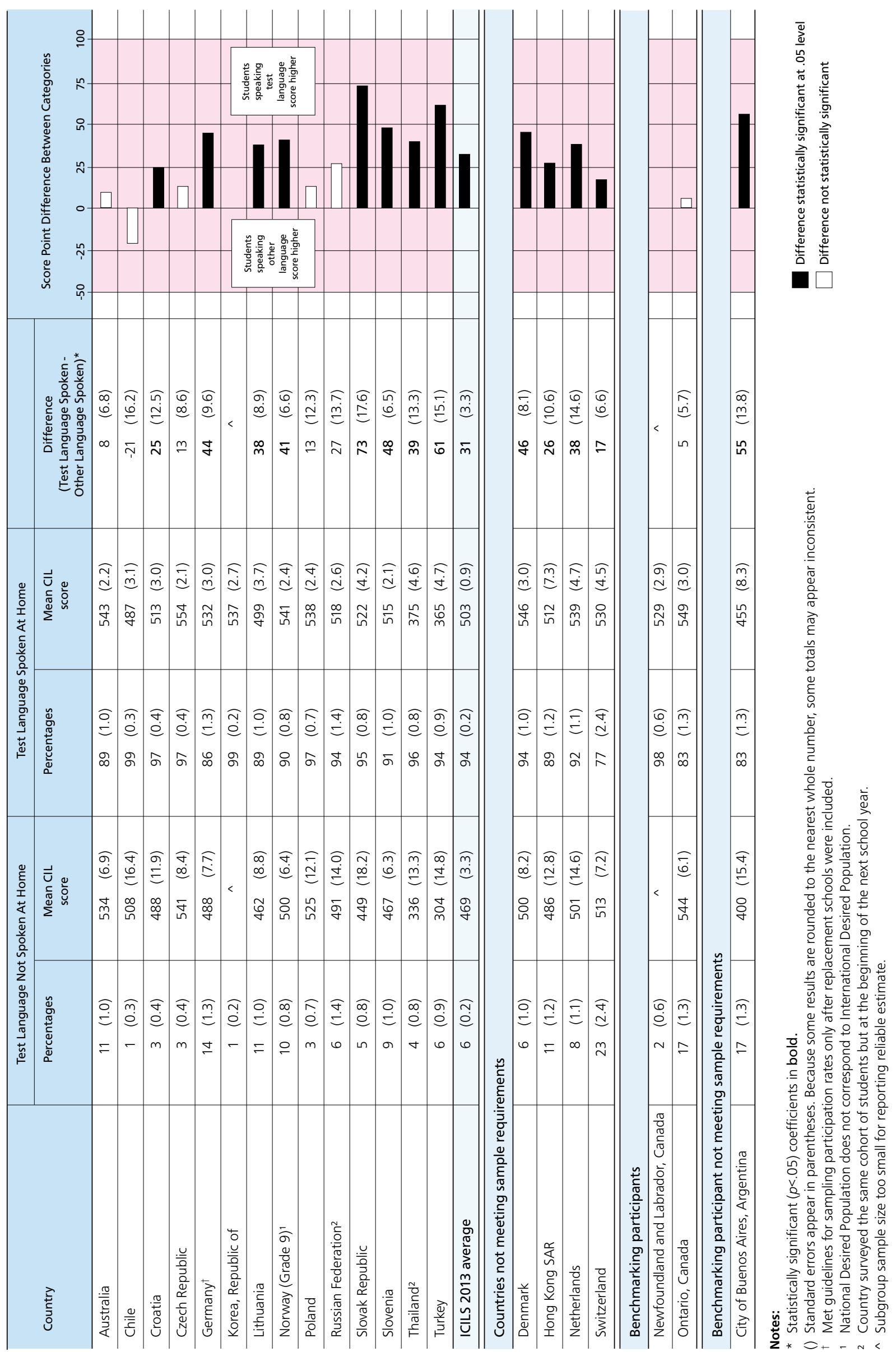




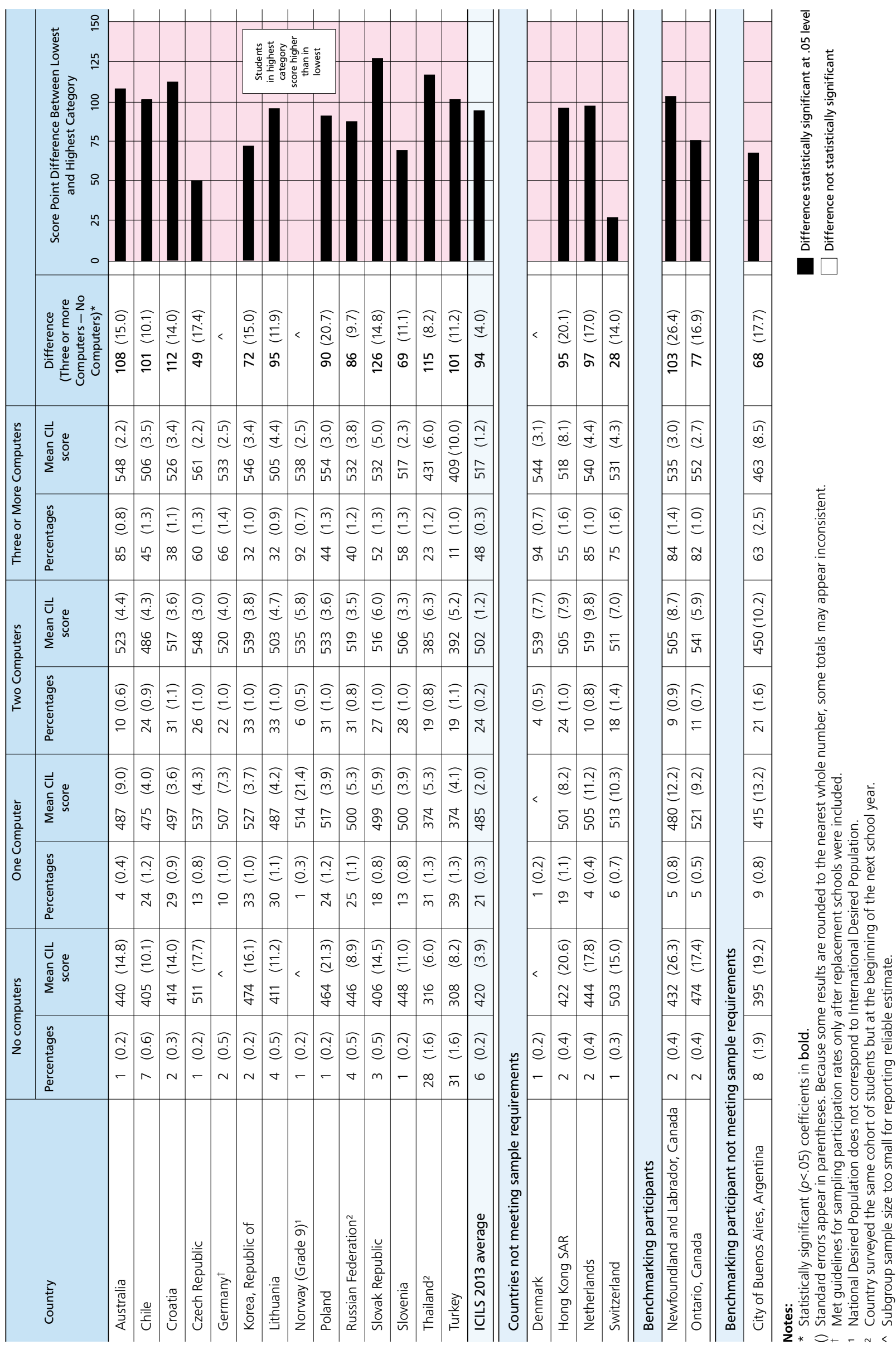


As we expected, these percentages varied among countries. Although, in most countries, only very small percentages (below 5\%) reported not having any computers at home, this was the case for every third student in Thailand and Turkey. Large majorities in Australia and Norway (85\% and $92 \%$ respectively) as well as the two Canadian provinces of Ontario and Newfoundland and Labrador (82\% and $84 \%$ respectively) said they had three or more computers at home. Only one in 10 Turkish students had this level of computer resourcing at home.

Students with more computers at home tended to have higher CIL scores. On average across countries, the difference in score points between students reporting three or more computers and those who indicated no computers at home was 94 points. This difference ranged from 49 points in the Czech Republic to 126 points in the Slovak Republic. In three countries (Germany, Norway, and Denmark), no comparisons could be reported because of the very small number of students in the no computers at home category.

The ICILS student questionnaire also asked students about the type of internet access they had at home. The question had five response categories: "no internet," "dial-up connection," "broadband," "connection through a mobile phone network," and "have internet at home but do not know what type of connection." Given that a number of students were not able to provide information on the type of internet access at home, only students with and without access were distinguished for the analysis in this report. The percentages of students who provided data on internet access at home averaged 99 percent across countries.

As Table 4.9 illustrates, internet access at students' homes varied across countries. While, in most countries, no more than five percent of students reported not having any access to the internet, larger proportions were recorded as having no internet access in Chile (10\%), Turkey (37\%), and Thailand (43\%).

Across countries, students with no internet access at home had lower CIL average scores than those who reported having this access at home. On average, students without internet access scored 72 points lower on CIL than those who reported having internet access. Statistically significant differences ranged from 38 score points in the Czech Republic to 120 in the Slovak Republic. In a number of countries (Germany, Norway, Denmark, Hong Kong SAR, the Netherlands, Switzerland, and Newfoundland and Labrador), the subgroup of students who said they had no internet access at home was too small to permit valid reporting of CIL average scores and comparison with the other group.

\section{Influence of combined home background variables on CIL}

To analyze the combined effects of the home background variables, including gender, on CIL, we used the following three blocks of predictor variables in a multiple regression model:

- Immigrant background and language use;

- Socioeconomic background (parental occupation, parental educational attainment, and home literacy resources); and

- ICT resources at home. 


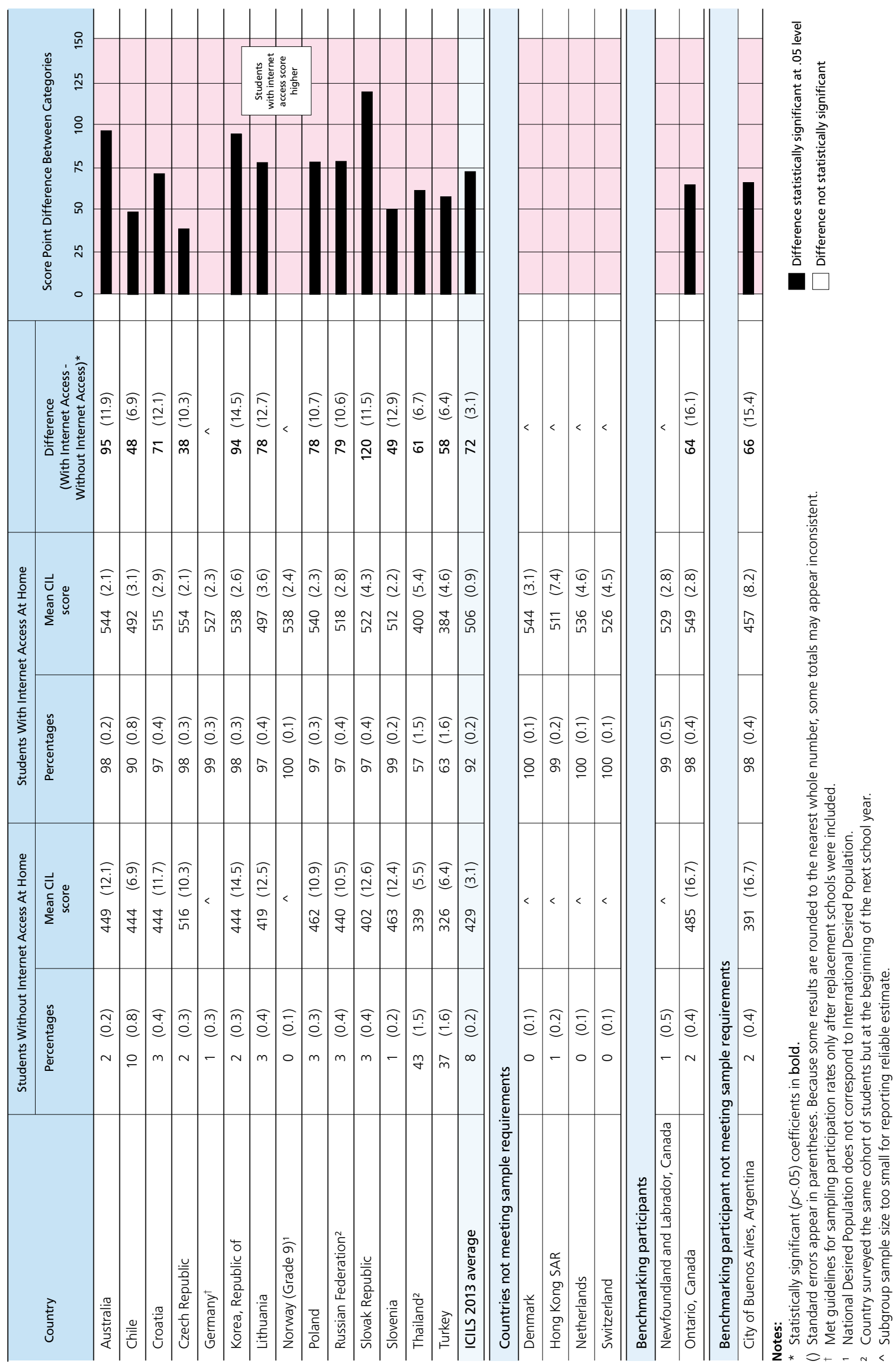


In the previous section, we documented the associations between these variables and CIL that we observed when we compared CIL scores across the reporting categories. In this section, we present the findings of our regression analysis. This analysis allowed us to study the net effects of each indicator variable after controlling for all other variables. We coded the predictor variables as follows:

- Gender: Female students were assigned a code of one; male students were assigned a code of zero. The regression coefficients indicate the difference in CIL score points between males and females after we had controlled for the effects of all other variables.

- Expected educational attainment: The categorical nature of the variable and our observation that the association with CIL was not linear in all countries led to the development of three dummy indicator variables: "expected lower-secondary education or below," "expected post-secondary nonuniversity education," and "expected university education." We assigned a value of one for each variable if the student was in that category and a value of zero if they were not in that category (i.e., the remaining students). The category "expected upper-secondary education" was the reference group. Those students were assigned a value of zero for all three dummy variables. The regression coefficients indicate the difference in CIL score points between the respective category and students who anticipated that uppersecondary education would be their highest level of attainment (the reference group). ${ }^{4}$

- Parental educational attainment: As with students' expected education, three dummy variables indicated the highest level of parental educational attainment: "both parents with lower-secondary education or below," "at least one parent with post-secondary nonuniversity education," and "at least one parent with university education." For each dummy variable, we assigned a value of one if parental education was in the category and a value of zero to all other students (i.e., those not in the category). Parental education at the upper-secondary level was chosen as the reference group. The students in this group received a value of zero for all three dummy indicators. The regression coefficients indicate the net difference in CIL score points between the respective category and students whose parents had upper-secondary education as their highest level of attainment (the reference group).

- Parental occupational status: Occupational status (SEI) scores were standardized to have a mean of zero and a standard deviation of one across equally weighted ICILS countries. The regression coefficients indicate increases in CIL corresponding to an increase in SEI scores of one standard deviation.

- Home literacy resources: Because the increase in CIL score points across the four reporting categories was approximately linear (among and within countries), the indicator variable had four categories, with a value of zero assigned to students with "0-10 books at home," a value of one to those with "11-25 books at home," two to those with " $26-100$ books," and three to those with " 100 or more books." The regression coefficients indicate the increase in CIL points from one home literacy category to the next higher category.

- Computer resources at home: The "number of computers at home" categories ranged from "no computers" (assigned a value of zero) to "three computers or more"

4 Another way of expressing this is that we did not include, with respect to expected educational attainment, "uppersecondary education" in the model as a dummy variable. It therefore became the reference category for the dummy variables of the other categories. We applied an analogous procedure for parental education. 
(assigned a value of three). The regression coefficients indicate the increase in CIL points from one category to the next.

- Internet access at home: Students who reported having internet access at home were coded as one and those with no internet access were coded as zero. The regression coefficients indicate the net difference in CIL score points between students with and without internet access.

Students with missing data for any of the predictor variables were excluded from the regression analysis. Across the participating countries, about 93 percent of students with valid data for all variables were included in the regression model. Data from the Netherlands could not be included in the analysis because it did not provide data on parental occupational status.

Some indicator variables reflected results from very small subgroups (fewer than 30 students) in a number of countries. This was the case for expected lower-secondary education in Chile and also in a number of countries for internet access at home. In these cases, we included the variables in the analyses but did not report the corresponding regression coefficients in the tables because we considered these insufficiently reliable.

Table 4.10 shows the results from the multiple regression analysis. The table sets out, for each predictor, the unstandardized regression coefficients for each national dataset and the ICILS (international) averages along with their respective standard errors.

After controlling for other personal and social background variables, we found that being female had a positive and statistically significant effect in seven of the 14 participating countries meeting sampling requirements as well as in the two Canadian benchmarking participants (Newfoundland and Labrador and Ontario). On average, the effect recorded was 10 score points. The largest regression coefficient was found amongst Korean students (33 score points).

Statistically significant associations between students' expected educational attainment (which ICILS considers to be a measure of educational aspiration) and CIL emerged across all participating countries. After controlling for all other predictor variables, we found that expectation of completing a university degree compared to expectation of no more than an upper-secondary education had an effect of (on average) 43 score points across countries. Expectation of completing a post-secondary nonuniversity qualification had (on average) a positive effect equivalent to 20 score points. Expectation of an education that went no further than lower-secondary school had a negative effect of -20 score points.

Having controlled for all other indicators, we noted that highest parental educational attainment had statistically significant positive effects on CIL in Australia, Chile, the Czech Republic, Lithuania, Poland, the Slovak Republic, Slovenia, Thailand, and Turkey. On average, having parents whose level of attainment was lower-secondary education or below had a negative effect of -12 score points (when compared to the reference category; that is, parental educational attainment at the level of upper-secondary only).

In three countries (the Czech Republic, Slovenia, and Turkey), having at least one parent with a university degree had statistically significant negative effects on CIL. When interpreting this result, we need to be mindful that these results refer to net effects after controlling for the effects of other indicators that may be associated with 


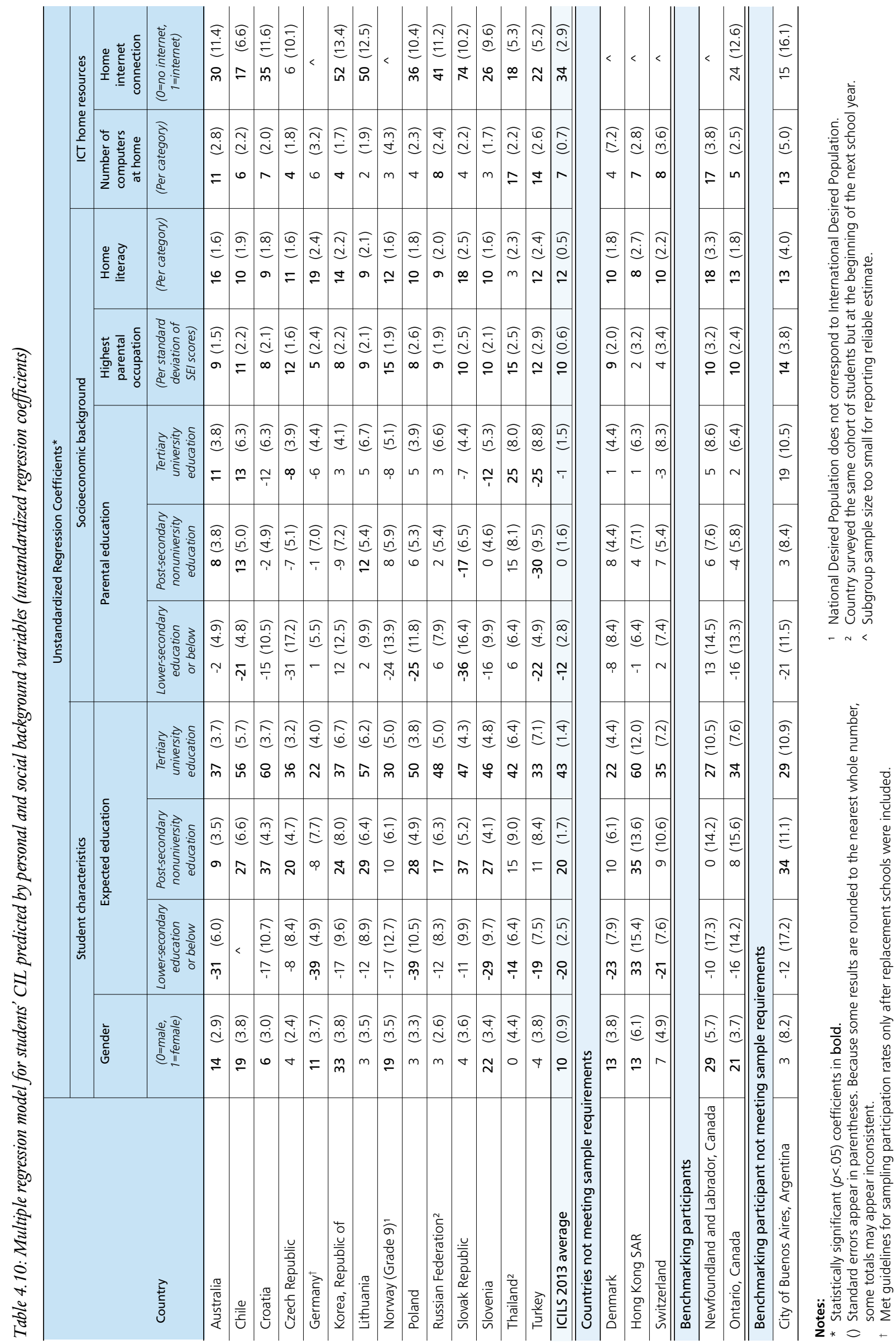


both parental education and CIL. ${ }^{5}$ This caveat is also relevant to interpretation of the results of other regression analyses reported in the following paragraphs.

In all participating countries, parental occupational status had statistically significant positive effects on CIL net of other background indicators. On average, an increase of 10 CIL points was associated with an increase of one standard deviation of SEI scores, with the differences ranging from five points in Germany to 15 points in Norway and Thailand. In all participating countries and benchmarking participants meeting sample participation requirements, except Thailand, home literacy resources had positive net effects on CIL.

Across the ICILS countries, an increase in one home literacy category was associated with an increase of 12 CIL score points. The largest effects were recorded for Germany (19 score points) as well as the Slovak Republic and the Canadian province of Newfoundland and Labrador (18 score points apiece).

In eight of the 14 ICILS countries that met sampling requirements and also in the two Canadian provinces (Newfoundland and Labrador and Ontario), availability of computers at home had statistically significant net effects on CIL. Across countries, each additional computer was associated with an increase of seven CIL score points, with the largest effects recorded for Thailand (17 score points), Turkey (14 score points), and the benchmarking participant Newfoundland and Labrador (17 score points). Internet access at home had a positive effect equivalent to 34 score points across the ICILS countries. Statistically significant positive net effects were recorded in most countries. The largest effects were found in the Slovak Republic (74 score points), Korea (52 score points), and Lithuania (50 score points).

Within a multiple regression model, the combined effect of more than one predictor or block of predictors can explain variance in the criterion variable. This facility makes it possible to estimate how much of the explained variance is attributable uniquely to each of the predictors or blocks of predictors, and how much of this variance is explained by these predictors or blocks of predictors in combination. We carried out this estimation by comparing the variance explanation of three additional regression models (each time leaving out one of the three blocks of predictors) with a model that had all predictors in combination. ${ }^{6}$

Table 4.11 indicates how much variance was explained by the model as well as the relative contribution of the subsets of indicators. The table shows the explained variances $\left(R^{2 *} 100\right)$ and their standard errors. The graph at the right side of the table depicts the size of the explained variance and the proportions of common variance as well as the variance uniquely attributable to each of the three predictor blocks.

The multiple regression model explained, on average, 22 percent of the variance in CIL scores. The range extended from 14 percent in Korea to 29 percent in Thailand. Across and within most countries, the largest part of the explained variance could be uniquely attributed to indicators of students' personal background (on average $7 \%$ of the total variance in CIL) while socioeconomic indicators uniquely explained about four percent of the variance in CIL. Only a relatively small proportion of the variance was due to a unique contribution from ICT resources (on average less than 1\%).

5 A description of unadjusted effects can be found in the discussion pertaining to Tables 7.1 to 7.9 in Chapter 7 .

6 The differences between each of the comparison models with the full model provide an estimate of the unique variance attributable to each block of variables. The difference between the sum of block variances and the explained variance by all predictors provides an estimate of the common variance attributable to more than one block of variables. 
Table 4.11: Multiple regression model for students' CIL predicted by personal and social background variables (explained variance estimates)

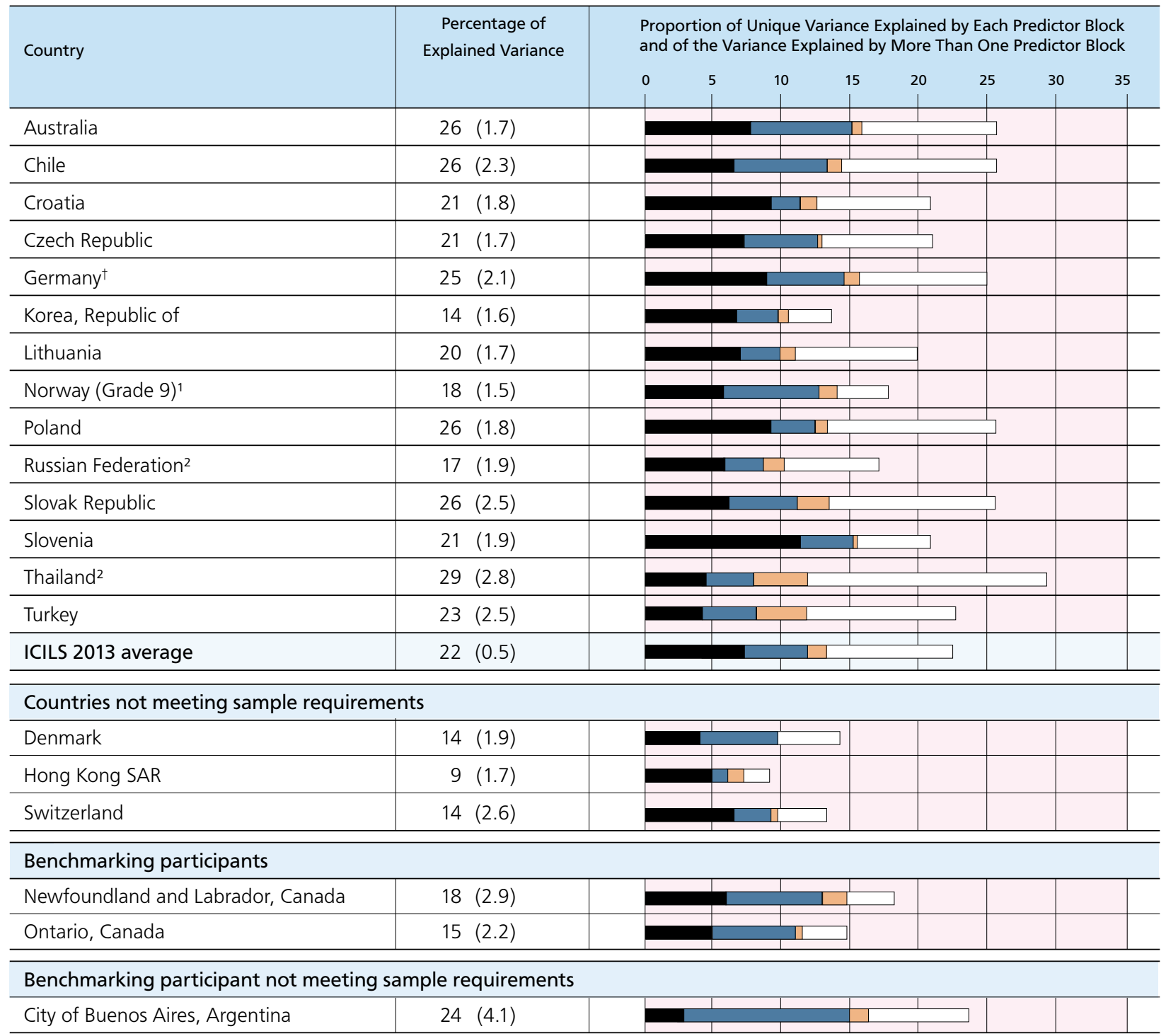

Notes:

() Standard errors appear in parentheses. Because some results are rounded to the nearest whole number, some totals may appear inconsistent.

$\dagger$ Met guidelines for sampling participation rates only after replacement schools were included.

1 National Desired Population does not correspond to International Desired Population.

2 Country surveyed the same cohort of students but at the beginning of the next school year.

Variance uniquely explained by student characteristics

Variance uniquely explained by parental occupation, parental education, and number of books

$\square$ Variance uniquely explained by IT home resources

$\square$ Variance explained by all factors 
There was also a substantial proportion of variance due to more than one factor (9\% of the total variation in CIL across countries). In Thailand, in particular, the model explained 29 percent of the variation in CIL, with more than half of this explained variance due to more than one predictor block. This finding is plausible given that many indicators are likely to be associated with one another. For example, ICT resources are likely to be more often found in households with higher socioeconomic status, and parents' educational attainment is likely to influence students' expected educational attainment.

\section{Conclusion}

In this chapter, we reviewed the associations between students' personal and social background factors and CIL. Because of the likelihood that development of CIL is influenced not only by students' individual characteristics and their respective socioeconomic background but also by the extent of access students have to computers and the internet, we included ICT resources in students' homes in our analyses.

We found that personal characteristics such as gender and expected educational attainment as well as socioeconomic indicators consistently explained a considerable amount of the variance in CIL test scores. Both gender and students' educational aspirations were associated with higher levels of CIL. Among the socioeconomic indicators, parental occupational status and home literacy resources in particular were positively associated with CIL across the participating countries.

We also found that availability of home ICT resources had a positive effect on CIL in many countries. In particular, home access to the internet appeared to be associated with the higher CIL scores among students. The results of our multiple regression analysis, which enabled us to review the net effects on CIL as well as the unique variance contributions of different predictor blocks, suggest that ICT resources may also reflect (in part) the socioeconomic status of students' homes. Another observation is that in some highly developed countries, home ICT resources have only minor effects probably because students in almost all households in these countries have computers and internet access.

When we combined all home background variables into a multivariate analysis model, the variables that emerged as the most consistent predictors were expected university education, parental occupational status, and home literacy resources as well as the availability of internet access. The model explained about a fifth of the variation in CIL on average. However, in some countries, this proportion was more than one quarter.

These findings suggest that while personal and social background does not predict large proportions of the variance at the individual level, it is nonetheless important to take these factors into account when explaining variation in CIL. In Chapter 8, we review a wider range of potential predictors of CIL variation. There we use hierarchical linear modeling to explore the extent to which factors at both the individual (including personal and social background indicators) and the school level explained student performance on the ICILS assessment of computer and information literacy.

Open Access. This chapter is distributed under the terms of the Creative Commons Attribution Noncommercial License which permits any noncommercial use, distribution, and reproduction in any medium, provided the original author(s) and source are credited.

All commercial rights are reserved by the Publisher, whether the whole or part of the material is concerned, specifically the rights of translation, reprinting, re-use of illustrations, recitation, broadcasting, reproduction on microfilms or in any other way, and storage in data banks. Duplication of this publication or parts thereof is permitted only under the provisions of the 
Copyright Law of the Publisher's location, in its current version, and permission for commercial use must always be obtained from Springer. Permissions for commercial use may be obtained through RightsLink at the Copyright Clearance Center. Violations are liable to prosecution under the respective Copyright Law.

The use of general descriptive names, registered names, trademarks, etc. in this publication does not imply, even in the absence of a specific statement, that such names are exempt from the relevant protective laws and regulations and therefore free for general use. 